reputation for precise work," says one Western researcher, expressing a commonly held view. If Zeiss-Jena were to go under, he adds, it would be "the end of an era".

Outside analysts say that the worst can indeed be avoided. One analyst from the US consulting firm SRI International, which is developing a concept for the reconstruction of the optoelectronics industry in the Jena region, says that the ability to do such hightechnology projects as the hexapod telescope distinguishes Zeiss-Jena from eastern German companies in other fields. This may help buy time for the company, he says. Assuming - and this is the key assumption that sufficient financial support and retraining of workers is provided over the next five years or so, the analyst says he sees an "excellent chance" for Zeiss-Jena to survive, either as one company or a number of smaller ones.

Zeiss-Jena managers say their strategy includes plans to develop or expand in new

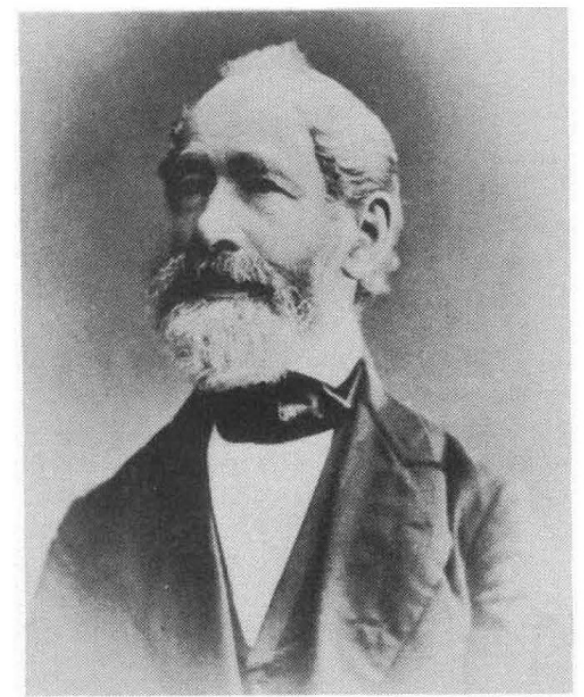

Carl Zeiss, founder of the optics company, pictured in about 1885 .

areas, such as lasers for medical and measuring applications, optical coatings and devices and digital image-processing, in addition to trying to expand sales to the West in Zeiss's traditional strengths - predominantly microscopes and measurement technology.

Whatever happens, Zeiss-Oberkochen is likely to play a major role in its long-lost sibling's future. The company was very annoyed at being shut out of the original talks between Thuringia and the trust body, and now it says that, if necessary, it is ready to go to battle over Zeiss-Jena. If the company is given to Thuringia, then Zeiss-Oberkochen may well go to court to determine who has the rights to the Zeiss name, says Manfred Berger, a spokesman for the western German company. "But we're still assuming we'll find a mutually acceptable solution."

Until then, Western researchers and Zeiss employees will be watching closely to see if capitalism can do in less than two years something that even 45 years of Communism could not achieve: destroy the historic Carl Zeiss-Jena.

Steven Dickman

\title{
Tough times in South Africa
}

\section{Johannesburg}

THE South African research councils and the universities are faced with their toughest financial constraints ever, following the budget recently delivered to parliament by Minister of Finance Barend du Plessis. The budget was characterized by large increases in spending on police (to attempt to curb civil unrest) and foreign affairs (to establish new missions abroad in the wake of the thaw in South Africa's foreign relations), but little or nothing more for research.

Despite an increase in government spending of 14 per cent (roughly in line with inflation), four of the five research councils suffered cuts in their parliamentary grants. The 1991-92 allocations to the councils were as follows (with percentage increase or decrease in brackets):

- Council for Industrial and Scientific Research (CSIR), R207m (£44.23m)

$(-2.4 \%)$;

- Foundation for Research Development (FRD), R109m ( $£ 23.29 m$ ) (-4.8\%);

- Human Sciences Research Council (HSRC), R61m (£13.03m) (-1.9\%);

- Council for Mineral Technology (Mintek), R52m (£11.11m) (+2.7\%);

- Medical Research Council (MRC), R39m $(£ 8.33 \mathrm{~m})(-5.0 \%)$

The variation in allocations can be explained by the fact that the councils are funded through different government departments, which fared differently at the

\section{ANIMAL RESEARCH Challenge on testing}

Washington

As the battle lines of the animal-rights struggle shift, animal toxicity tests such as the LD-50 and Draize procedures have become the subject of challenges across the United States and in Congress. Last month, both the California and Vermont state assemblies passed bills outlawing skin-irritation and ocular (including Draize) testing on animals in the state. The bills will now be voted on in their respective state Senates. Since 1987, the number of states that have considered such legislation had tripled, to nine in 1990 . Six are already debating animal-testing bills this year, and more are expected before the end of the year.

In the US Congress, Senators Harry Reid (Democrat, Nevada) and Barbara Boxer (Democrat, California) intend to introduce bills to restrict or outlaw animal testing for cosmetics and household products. Although both have tried and failed to pass such legislation in the past, research advocates consider the new bills to be a serious threat. "The trend is obvious," says Barbara Rich, executive vice-president of the National Association for Biomedical Research. "Toxicity testing will be the big issue this session". Christopher Anderson hands of the Treasury. The cuts inflicted on the CSIR and MRC were lower than those in their funding departments' budgets: Trade and Industry and Health received cuts of 25.3 per cent and 12.1 per cent respectively. Mintek received its increase despite a 5.8 per cent cut in the budget of the Department of Mineral and Energy Affairs. The remaining councils, the FRD and the HSRC, along with the universities and national museums, are funded through the Department of National Education, which received a 1.6 per cent increase in its budget. The universities received exactly the same subsidies as last year, but at least negotiated their way out of a cut (see Nature 348, 183; 1990). The national museums, including the largest natural history museum, have also suffered severe cuts for the first time.

The CSIR, which is responsible for technologically orientated research conducted by its own laboratories, raised 46 per cent of its budget last year by contract work done for the private sector and government departments. According to its president, Dr Brian Clark, it hopes to increase this figure to 51 per cent this year, providing for an overall planned growth in income of 8 per cent. The FRD, MRC and HSRC are responsible for the provision of studentships, as well as the funding of research at universities, technikons and museums, so this sector is set to suffer most.

Michael Cherry

\section{The end for monkeys}

\section{Washington}

GoverNMENT scientists experimented on and killed two of the last four remaining 'Silver Spring monkeys' last week after a last-minute legal battle that reached the US Supreme Court.

Officials at the National Institutes of Health (NIH) said the animals were dying of complications from previous injuries. Rescued by activists in 1981 from a laboratory in Silver Spring, Maryland, the monkeys have been a cause célèbre for the animal rights movement and the symbolic poster children of antivivisectionism.

Last week, the activist group People for the Ethical Treatment of Animals appealed to the Supreme Court after failing in lower courts to gain a restraining order so that the poor health of the animals could be confirmed by an independent veterinarian. Although the high court temporarily halted the experiment for one day, it permitted the killing of the monkeys after NIH said the animals were in pain, had ceased eating and would soon die. NIH researchers placed the animals under "terminal anesthesia" before examining their brains for signs of neural reorganization as an adaptation to injuries suffered in the original Silver Spring experiment. 